EXTENDED REPORT

\title{
Inflammation in ankylosing spondylitis: a systematic description of the extent and frequency of acute spinal changes using magnetic resonance imaging
}

\author{
X Baraliakos, R Landewé, K-G Hermann, J Listing, W Golder, J Brandt, M Rudwaleit, \\ M Bollow, J Sieper, D van der Heijde, J Braun
}

Ann Rheum Dis 2005;64:730-734. doi: 10.1136/ard.2004.029298

See end of article for authors' affiliations

Correspondence to: Professor J Braun, Rheumazentrum

Ruhrgebiet, Landgrafenstr 15,44652 Herne, Germany; j.braun@ rheumazentrumruhrgebiet.de

Accepted

18 September 2004

Published Online First

30 September 2004

\begin{abstract}
Background: Magnetic resonance imaging (MRI) is increasingly used to detect inflammation in the spine of patients with ankylosing spondylitis (AS).

Objectives: To detect differentially the presence and extent of inflammation in the three spinal segments of patients with AS by MRI.

Methods: In 38 patients with active AS, acute spinal lesions were assessed by $T_{1}$ weighted, gadolinium enhanced, spin echo MRI ( $\left.T_{1} / G d-D T P A\right)$ and short $\tau$ inversion recovery (STIR) sequences. MRI was quantified by the validated scoring system ASspiMRI-a. Acute spinal lesions were detected in the whole spine and in each spinal segment. One vertebral unit (VU) was defined as the region between two virtual lines drawn through the middle of each vertebral body.

Results: A greater number of inflammatory spinal lesions were found by the STIR sequence than by GdDTPA: inflammation was present in $30.6 \%$ of the VUs as assessed by STIR, compared with $26.8 \%$ of the same VUs assessed by $T_{1} / G d-D T P A$. Inflammation was found more commonly in the thoracic spine (TS) than in the cervical (CS) or the lumbar spine (LS) with both techniques. When STIR was used, spinal inflammation in the CS, the TS, and LS was detected in 10/38 (26\%), 28/38 (74\%), and 9/38 (24\%) patients, respectively. The VU T7/8 was found to be the VU most offen affected by both techniques $(27.8 \%$ by $\mathrm{T}_{1} /$ Gd-DTPA and $34.5 \%$ by STIR).

Conclusions: Spinal inflammation is a common manifestation in patients with AS, and appears more frequently in the TS. The scoring system ASspiMRI-a can be used for evaluation of acute spinal changes in
\end{abstract} AS.
A nkylosing spondylitis (AS), the prototype of the spondyloarthritides, ${ }^{1}$ starts in the sacroiliac joints and may extend to the spine in the majority of patients with inflammatory back pain as its leading symptom. ${ }^{2}$ Sacroiliitis, spondylitis, spondylodiscitis, and spondyloarthritis are the main inflammatory manifestations. ${ }^{3}$ There is increasing evidence that new imaging tools such as magnetic resonance imaging (MRI) are a major advance in the assessment of spinal inflammation in AS and other diseases, ${ }^{3}$ although conventional $x$ ray examinations are still the preferred method for imaging of chronic spinal changes in AS; this is especially true for long term studies. ${ }^{4}$

Anti-tumour necrosis factor agents have dramatically changed the therapeutic strategies in AS, because both infliximab and etanercept have shown strong clinical efficacy in the short and intermediate term..$^{5-9}$ Importantly, the improvement in clinical disease activity was shown to correlate with the amelioration of acute spinal changes, as documented by $\mathrm{T}_{1}$ weighted post-gadolinium-diethylenetriamine-pentaacetic acid (Gd-DTPA) and short $\tau$ inversion recovery (STIR) follow up MRI examinations. ${ }^{10}$

The thoracic spine is difficult to visualise by conventional radiography, so scoring of acute and chronic spinal lesions in this region is not part of established radiological scoring systems, which assess only the lumbar and cervical spine. Therefore, our knowledge about the presence of acute and chronic spinal lesions in the thoracic spine has been rather limited to date. The differential involvement of spinal segments by inflammation has not been systematically analysed until now.
The main aim of this study was to assess the presence and extent of inflammation in all three spinal segments in patients with AS by $T_{1}$ weighted, fat saturated, post-GdDTPA and STIR MRI sequences, and to compare the differential involvement of the three spinal segments.

\section{PATIENTS AND METHODS}

\section{Patients' characteristics}

The 38 patients with AS examined had been referred to the university outpatient clinic because of back pain due to AS. Some patients were candidates for inclusion in the large randomised controlled trial on the efficacy of infliximab in AS performed in Germany. ${ }^{5}$ All had been conventionally treated with non-steroidal anti-inflammatory drugs before inclusion in this study. None of them had ever been treated with biological agents. Of the 38 patients, 24 (63\%) were male. The mean age of the patients was 40.9 years (range $32-$ 54); 35 (92\%) were HLA-B27 positive. The mean (SD) erythrocyte sedimentation rate was $31.2(23.0) \mathrm{mm} / \mathrm{lst} \mathrm{h}$ and the mean (SD) C reactive protein was 22.2 (21.9) $\mathrm{mg} / \mathrm{l}$. The patients had active disease with a mean (SD) Bath AS Disease Activity Index (BASDAI) of 6.4 (1.4) and Bath AS Functional Index (BASFI) of 5.5 (2.1) (table 1). Before the study, the diagnosis AS was confirmed by radiological examination of the sacroiliac joints in all patients.

Abbreviations: AS, ankylosing spondylitis; CS, cervical spine; GdDTPA, gadolinium-diethylenetriamine-pentaacetic acid; LS, lumbar spine; MRI, magnetic resonance imaging; STIR, short $\tau$ inversion recovery; TS, thoracic spine; $\mathrm{VU}$, vertebral unit 


\begin{tabular}{llllll} 
Table 1 & \multicolumn{4}{c}{ Demographic data of the 38 patients with AS } \\
\hline & Mean & Minimum & Maximum & SD \\
\hline Age (years) & 40.9 & 32 & 54.0 & 8.0 \\
Disease duration (years) & 14.9 & 2.0 & 34.0 & 8.6 \\
BASDAl score & 6.4 & 4.0 & 8.6 & 1.4 \\
BASFI score & 5.5 & 0.9 & 8.6 & 2.1 \\
BASMI score & 3.7 & 1.0 & 9.0 & 2.2 \\
CRP (mg/l) & 22.2 & 1.0 & 89.0 & 21.9 \\
ESR (mm/lst h) & 31.1 & 3.0 & 78.0 & 23.0 \\
\hline
\end{tabular}

BASDAI, Bath Ankylosing Spondylitis Disease Activity Index; BASFI, Bath Ankylosing Spondylitis Functional Index; BASMI, Bath Ankylosing Spondylitis Metronomy Index; CRP, C reactive protein; ESR, erythrocyte sedimentation rate.

\section{Magnetic resonance imaging (MRI)}

MRI investigations were executed with a $1.5 \mathrm{~T}$ unit Magnetom Vision (Siemens AG Medical Solutions, Erlangen, Germany), using a spine-array coil and/or a body-array coil. The MRI techniques applied to assess sacroiliac and spinal inflammation in patients with AS were performed as described previously. ${ }^{3}$ The sagittal section orientation was chosen and the following sequences were used:

- $\mathrm{T}_{1}$ weighted spin echo sequences (repetition time/echo time 500/14-20 ms, slice thickness 3-4 mm, two acquisitions) before, and

- The same sequence with fat saturation after application of Gd-DTPA (Schering AG, Berlin, Germany) at $0.1 \mathrm{mmol} / \mathrm{kg}$ body weight.

No dynamic imaging was performed. C2 and L5 were taken as orientation points and the spine was examined in two parts, always starting with the upper part. After rapid adjustment of the table into the appropriate position the lower part of the spine was examined.

- Similarly, STIR sequences (repetition time/inversion time/ echo time 4000/150/60 ms, slice thickness 3-4 mm, one acquisition) with intrinsic fat saturation were performed.

- $\mathrm{T}_{2}$ weighted images were also available and were taken into account when differentiation between chronic and acute lesions was doubtful.

\section{Scoring of spinal inflammation in MRI}

The MR images were blinded for patient identity and were then chosen by an independent person. Evaluation was performed by two readers (JB, WG), by evaluating each time first the $\mathrm{T}_{1} /$ Gd-DTPA and then the STIR MR images of one patient in each reading session. Each evaluation was performed twice by each reader (at different times). Thus, each image was evaluated four times in total.

\begin{tabular}{|l} 
ASspiMRI-a \\
$0=$ Normal, no lesions \\
$1=$ Mild enhancement and bone marrow oedema, covering $\leq 25 \%$ of a VU \\
$2=$ Moderate bone marrow oedema, covering $\leq 50 \%$ of a VU \\
$3=$ Severe bone marrow oedema, covering $>50 \%$ of a VU \\
$4=$ Bone marrow oedema and erosion covering $\leq 25 \%$ of a VU \\
$5=$ Bone marrow oedema and erosion covering $\leq 50 \%$ of a VU \\
$6=$ Bone marrow oedema and erosion covering $>50 \%$ of a VU
\end{tabular}

Figure 1 The new scoring system ASspiMRI-a for evaluation of acute spinal lesions in patients with ankylosing spondylitis as assessed by GdDTPA and STIR MRI.
The analysis of acute spinal changes in MRI was performed by evaluating the $\mathrm{T}_{1} /$ Gd-DTPA and STIR MRI sequences with the new MRI scoring system ASspiMRI-a (figs 1 and 2) ${ }^{10}{ }^{11}$ ), which is a part of the ASspiMRI score. ${ }^{10}$ This scoring system was developed by our group to assess acute spinal lesions by evaluating the enhancement in $T_{1}$ weighted MRI sequences after application of Gd-DTPA, and also by evaluating bone and bone marrow oedema in STIR MRI sequences (ASspiMRI-a ${ }^{10}{ }^{12}$ ). Chronic spinal lesions can also be evaluated by using $\mathrm{T}_{1}$ weighted MRI sequences (ASspiMRI-c, ${ }^{10}{ }^{13}$ ). These data have been reported in detail elsewhere. ${ }^{13}$

Spinal involvement due to AS was assessed by using the lateral view of the spine and evaluating spinal changes on the basis of vertebral units (VUs). One VU is defined as the region between two virtual lines drawn through the middle of a vertebral body (fig $3^{10}$ ).

Overall, 23 VUs from C2 to S1 were assessed by the ASspiMRI-a (6 VUs in the cervical spine (CS) from C2/3 to C7/Tl; 12 VUs in the thoracic spine (TS) from $\mathrm{Tl} / 2$ to $\mathrm{Tl} 2 / \mathrm{Ll}$, and 5 VUs in the lumbar spine (LS) from Ll/2 to L5/S1).

Acute spinal changes are graded by the ASspiMRI-a in a range between 0 and 6 (fig 1). Definite involvement of a VU in the evaluation of both MRI sequences indicates inflammation/oedema with and without erosion and it is defined as a VU score $>0$ in the ASspiMRI-a.

\section{Evaluation of the scoring}

The extent of inflammatory spinal disease due to AS was analysed by comparing the same VU in each of the two MRI sequences and by calculating these results on the basis of four different aspects: $(a)$ the mean score of the four readings for each single $\mathrm{VU} ;(b)$ the inflammation seen in each VU (affection by the disease or not); (c) the involvement of each spinal segment; and $(d)$ the analysis of each individual patient.

\section{Statistical analysis}

The reliability of the scoring system with an inter- and intrarater variance and also the correlation coefficients between the scores are presented elsewhere. ${ }^{14}$

Spinal activity was analysed for a single VU, for a spinal segment, on for the spine, and for a single patient, for each MRI sequence.

Comparisons between the $\mathrm{T}_{1} /$ Gd-DTPA and STIR sequence scores were performed by first calculating the means of the four readings for each VU for each sequence and then by comparing similar VUs for each sequence. Statistical comparison of the scores in the two MRI sequences was performed by the Wilcoxon test.

For the assessment of inflammation at the patient-level, both readers had to score positive findings in the same patient for confirmation of inflammation. VUs with scores " 1 " to " 6 " were considered positive for inflammation, whereas VUs with a score " 0 " were considered negative for inflammation. Proportions of affected VUs for each sequence (STIR, post-Gd-DTPA) in the same patients were compared by the McNemar test.

\section{RESULTS}

Comparison of the $T_{1} /$ Gd-DTPA and the STIR sequence using the MRI activity score ASspiMRI-a

Spinal inflammation was most frequently found in the TS (mean score 0.69 and 0.74 per VU for $T_{1} /$ Gd-DTPA and STIR sequences. The other two segments were less frequently affected (mean score 0.24 and 0.28 in the CS and 0.41 and 0.34 in the LS for $\mathrm{T}_{1} / \mathrm{Gd}$-DTPA and STIR, respectively). Table 2 shows the means and standard deviations (SD).

The VUs which were found to be most commonly affected by inflammation were the same by both MRI techniques. As 


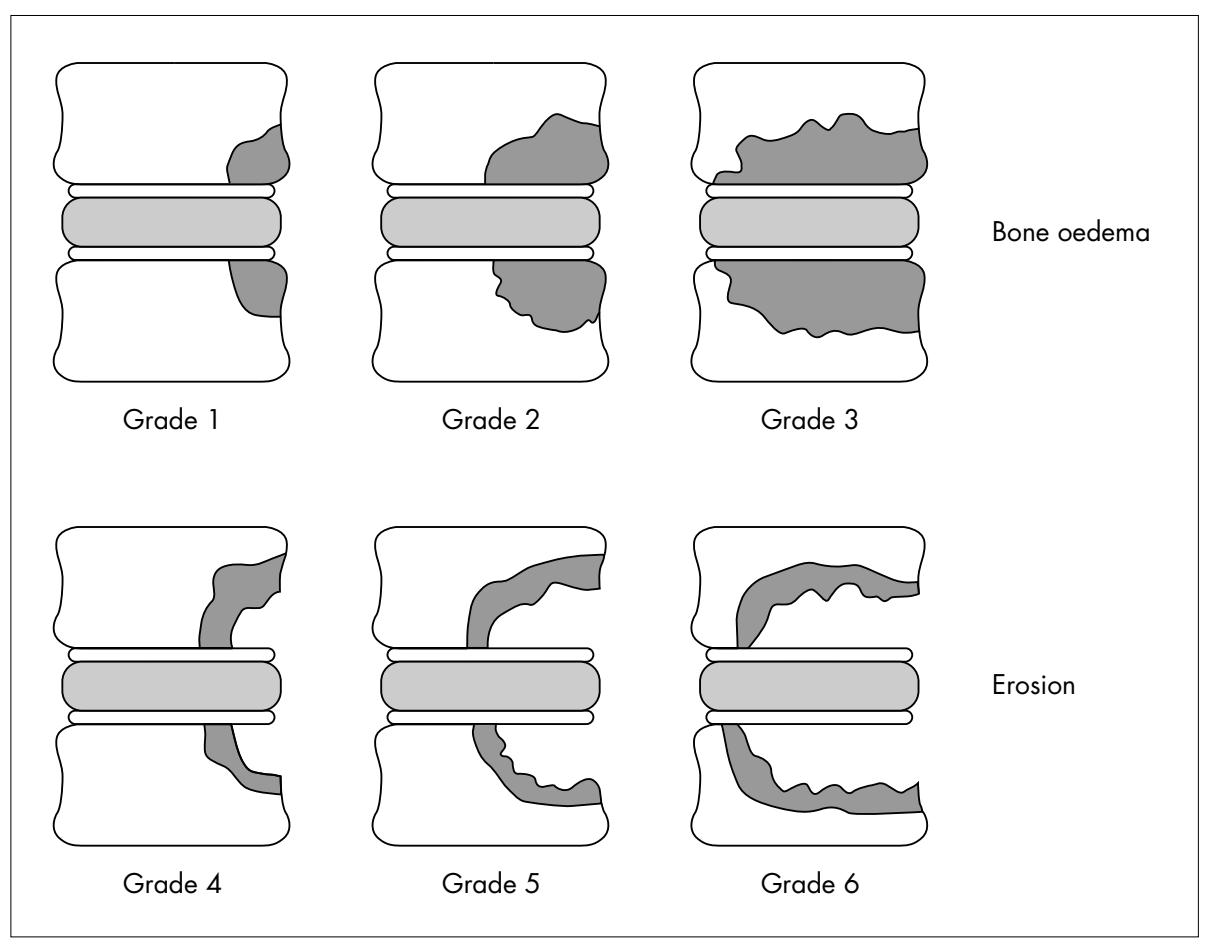

Figure 2 The ASspiMRI-a scoring system in detail. Grades 1-3 indicate only erosion with differentiation of the range of inflammation (in the Gd-DTPA sequence) or oedema (in the STIR sequence). Grades $4-6$ indicates inflammation with erosion, in relation to the extent of the erosion in the assessed $\mathrm{VU}$.

assessed by STIR, it was the VU C7/T1 in the CS $(26.2 \%)$, in the TS it was the VU T7/8 (53.7\% - this was also the VU most commonly affected in the whole spine (fig 6) - and in the LS it was the $\mathrm{VU} \mathrm{Ll} / 2(27.1 \%)$. Figures 4 and 5 show the numbers and proportions of all VUs, as assessed by both MRI techniques.

Definite inflammatory involvement of each spinal segment was found in $16 \%$ of the VUs of the CS by $\mathrm{T}_{1} / \mathrm{Gd}$-DTPA sequences and in $20.7 \%$ by STIR sequences, respectively $(\mathrm{p}<0.05)$. In the TS, $34.5 \%$ and $38.7 \%$ of the VUs $(\mathrm{p}<0.001)$ and in the LS $20.3 \%$ and $23 \%(p<0.05)$ of the VUs showed definite inflammation in the $\mathrm{T}_{1} /$ Gd-DTPA and STIR sequences, respectively.

In the whole spine, definite inflammation was found in $26.8 \%$ of the VUs in the evaluation of the $\mathrm{T}_{1} / \mathrm{Gd}$-DTPA sequence and in $30.6 \%$ in the evaluation of the STIR sequence $(\mathrm{p}=0.001)$.

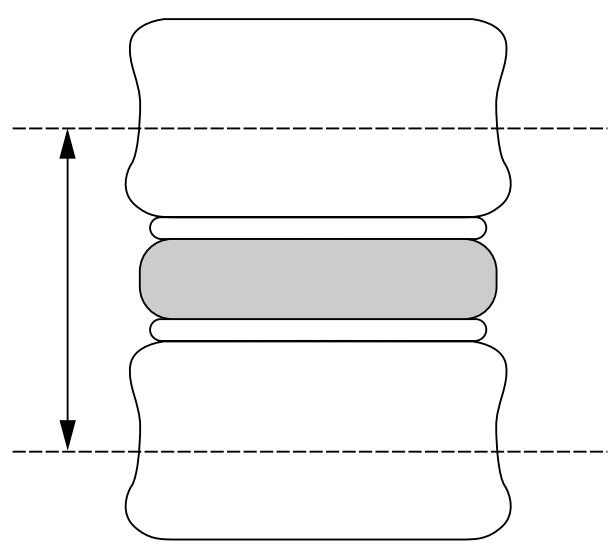

1 Vertebral unit

Figure 3 Definition of the VU for using the ASspiMRI score in the evaluation of MR images in the spine of patients with AS.
When analysing each patient individually, evaluation of the $\mathrm{T}_{1} /$ Gd-DTPA sequences showed that 9/38 (24\%) patients with AS had definite spinal inflammation in the CS, 28/38 $(74 \%)$ in the TS, and $7 / 38(18 \%)$ in the LS. Evaluation by STIR sequence showed definite inflammatory involvement in $10 / 38(26 \%), 28 / 38(74 \%)$, and $9 / 38(24 \%)$ patients for the CS, TS and LS, respectively.

\section{DISCUSSION}

This study shows that inflammation is a prevalent feature in AS, which can be assessed by MRI techniques such as $T_{1} / G d$ DTPA and STIR.

The scores of both magnetic resonance sequences confirm that the TS is more commonly affected by inflammation in AS than the other two spinal segments. This important finding is substantiated by the results of the analyses of the different levels assessed: a single VU, a spinal segment, and

Table 2 Descriptive data in the evaluation of acute spinal changes with mean scores for each spinal segment and for the whole spine as evaluated by the ASspiMRI-a for Gd-DTPA and STIR sequences

\begin{tabular}{lll}
\hline & Mean score/VU & SD \\
\hline Cervical spine & & \\
ASspiMRI-a Gd-DTPA & 0.24 & 0.63 \\
ASspiMRI-a STIR & 0.28 & 0.65 \\
& & \\
Thoracic spine & 0.69 & 1.24 \\
ASspiMRI-a Gd-DTPA & 0.74 & 1.22 \\
ASspiMRI-a STIR & & \\
& & \\
Lumbar spine & 0.41 & 1.04 \\
ASspiMRI-a Gd-DTPA & 0.34 & \\
ASspiMRI-a STIR & & 1.09 \\
Spine (all three segments) & 0.51 & 1.04 \\
ASspiMRI-a Gd-DTPA & 0.54 & \\
ASspiMRI-a STIR & & \\
\hline
\end{tabular}




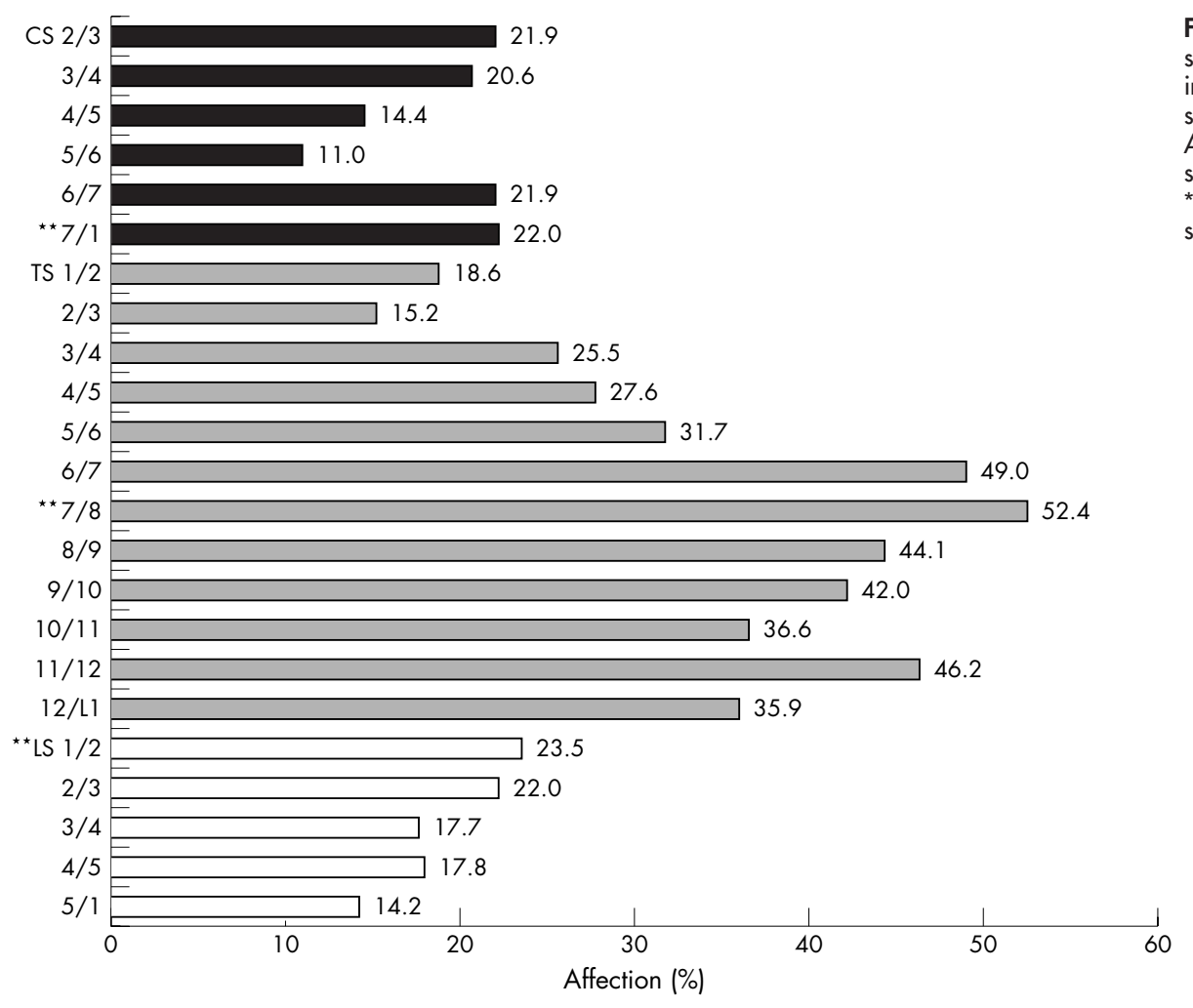

Figure 4 Relative involvement of each single $\mathrm{VU}$ in the assessment of inflammation by the Gd-DTPA MRI sequence and evaluation with the ASspiMRI-a scoring system. Values are shown as percentage of VU affected. ${ }^{*} \mathrm{VU}$ most commonly affected in each spinal segment.

an individual patient. The subanalysis of definite involvement provides conservative but solid data on active spinal inflammation in AS.

The analyses indicate that the preferential affection of the thoracic spine by AS is not solely explained by the greater number of VUs or vertebral bodies in the TS. Apparently, AS affects the TS and especially its lower part more frequently, to a greater extent, and with a greater inflammatory intensity. Other spinal disorders may also preferentially occur in the lower parts of the TS and the upper parts of the LS:

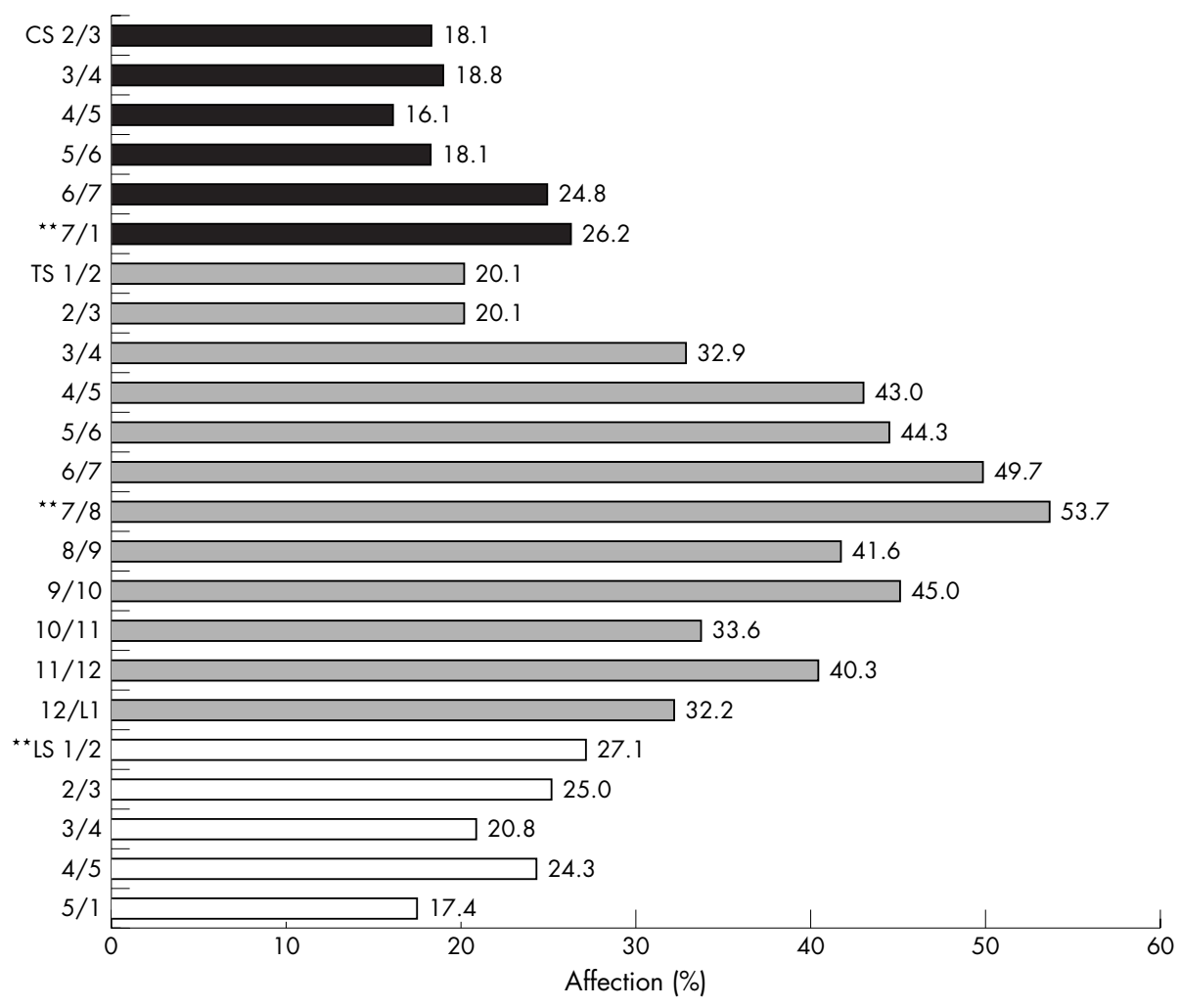

Figure 5 Relative involvement of each single $\mathrm{VU}$ in the assessment of inflammation by the STIR MRI sequence and evaluation with the ASspiMRI-a scoring system. Values are shown as percentage of $\mathrm{VU}$ affected. ${ }^{* *} \mathrm{VU}$ most commonly affected in each spinal segment. 


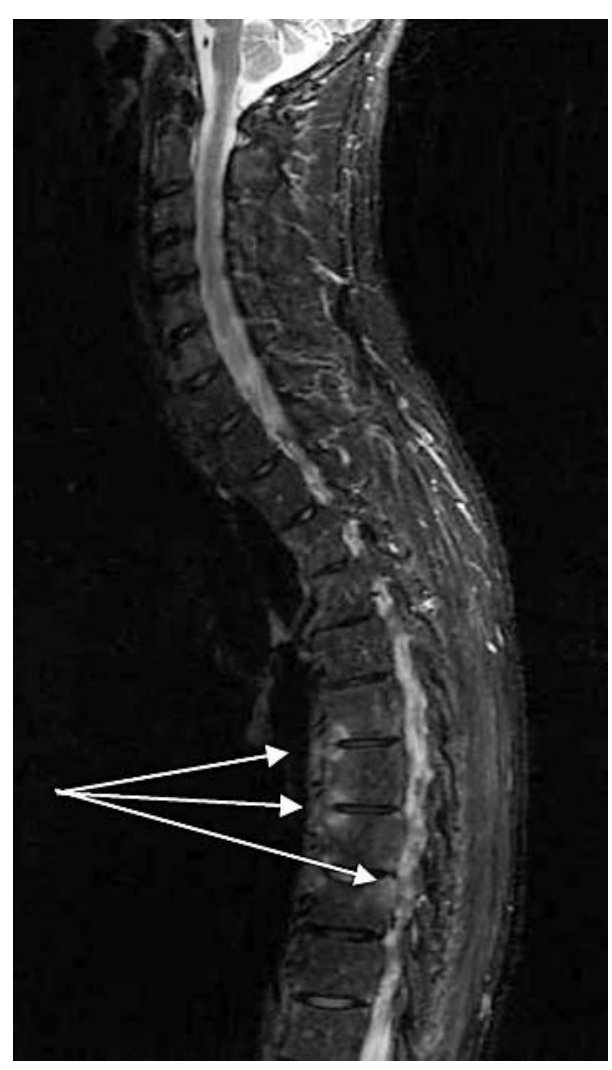

Figure 6 Spondylitis anterior in T6/7 and T7/8 and spondylitis posterior in T8/9 as seen in the STIR MRI sequence. Inflammation is seen as a spot in the vertebra (arrows).

osteoporotic fractures, intervertebral disc problems, and vertebral injuries. The lower TS and upper LS may reflect an area of higher vulnerability for reasons of statics. ${ }^{15-17}$

Indeed, as the more detailed analyses showed, the spinal region most commonly affected by inflammatory involvement in AS was the region between the middle part of the TS (T7/8) and the middle part of the LS (L2/3). This information is important for the question of which spinal region should be the main site of imaging in patients with AS in daily practice or in clinical studies. On the basis of this evidence, we suggest that at least the lower part of the TS and the LS should be included in MRI examinations in patients with active AS.

There is increasing interest in the assessment of disease activity and spinal inflammation by MRI because of the successful use of biological agents in AS, especially infliximab $^{59}$ and etanercept. ${ }^{78}$ Furthermore, $\mathrm{T}_{1}$ weighted postcontrast agent and STIR MRI techniques are being increasingly used to detect active spinal lesions in AS, especially in clinical trials, in order to evaluate whether inflammation "visibly" improves after treatment with anti-tumour necrosis factor agents.

Taken together, the ability of MRI to detect acute spinal changes may be a major step forward in imaging inflammation in AS. The TS is most commonly affected in AS. Such states can be assessed both by STIR and by $\mathrm{T}_{1}$ weighted, contrast agent enhanced MRI.

\section{Authors' affiliations}

X Baraliakos, J Brandt, J Braun, Rheumazentrum Ruhrgebiet, Herne, Germany

R Landewé, D van der Heijde, Department of Internal Medicine, Division of Rheumatology, University Hospital Maastricht, The Netherlands K-G Hermann, Department of Radiology, Charité Medical School, Berlin, Germany

J Listing, German Rheumatism Research Centre, Berlin, Germany W Golder, Department of Radiology, DRK Kliniken Westend, Berlin, Germany

M Rudwaleit, J Sieper, Department of Rheumatology, Charité Medical School, Campus Benjamin Franklin, Berlin, Germany

M Bollow, Department of Radiology, Augusta-Krankenanstalt, Bochum, Germany

\section{REFERENCES}

1 Braun J, Bollow M, Remlinger G, Eggens U, Rudwaleit M, Distler A, et al. Prevalence of spondylarthropathies in HLA-B27 positive and negative blood donors. Arthritis Rheum 1998;41:58-67.

2 Calin A, Porta J, Fries JF, Schurman DJ. Clinical history as a screening test for ankylosing spondylitis. JAMA 1977;237:2613-14

3 Braun J, Bollow M, Sieper J. Radiologic diagnosis and pathology of the spondyloarthropathies. Rheum Dis Clin North Am 1998;24:697-735.

4 Spoorenberg A, de Vlam K, van der Linden S, Dougados M, Mielants H, van de Tempel $\mathrm{H}$, et al. Radiological scoring methods in ankylosing spondylitis. Reliability and change over 1 and 2 years. J Rheumatol 2004;31:125-32.

5 Braun J, Brandt J, Listing J, Zink A, Alten R, Golder W, et al. Treatment of active ankylosing spondylitis with infliximab: a randomised controlled multicentre trial. Lancet 2002;359:1187-93.

6 Brandt J, Haibel H, Cornely D, Golder W, Gonzalez J, Reddig J, et al. Successful treatment of active ankylosing spondylitis with the anti-tumor necrosis factor alpha monoclonal antibody infliximab. Arthritis Rheum 2000;43:1346-52.

7 Davis JC Jr, van der Heijde D, Braun J, Dougados M, Cush J, Clegg DO, et al. Recombinant human tumor necrosis factor receptor (etanercept) for treating ankylosing spondylitis: a randomized, controlled trial. Arthritis Rheum 2003;48:3230-6.

8 Brandt J, Khariouzov A, Listing J, Haibel H, Sorensen H, Grassnickel L, et al. Six-month results of a double-blind, placebo-controlled trial of etanercept treatment in patients with active ankylosing spondylitis. Arthritis Rheum 2003;48: 1667-75.

9 Braun J, Brandt J, Listing J, Zink A, Alten R, Burmester G, et al. Two-year maintenance of efficacy and safety of infliximab in the treatment of ankylosing spondylitis. Ann Rheum Dis 2005;64:229-34.

10 Braun J, Baraliakos X, Golder W, Brandt J, Rudwaleit M, Listing J, et al. Magnetic resonance imaging examinations of the spine in patients with ankylosing spondylitis, before and after successful therapy with infliximab: evaluation of a new scoring system. Arthritis Rheum 2003;48:1126-36.

11 Braun J, van der Heijde D. Imaging and scoring in ankylosing spondylitis. Best Pract Res Clin Rheumatol 2002;16:573-604

12 Baraliakos X, Golder W, Brandt J, Rudwaleit M, Listing J, Sieper J, et al. Analysing acute spinal changes in ankylosing spondylitis - a systematic comparison of conventional $x$-rays with magnetic resonance imaging (MRI) using established and new scoring systems. Orlando, FL, USA: in 67th Annual Scientific Meeting of the American College of Rheumatology, 2003.

13 Braun J, Baraliakos X, Golder W, Hermann K-G, Listing J, Brandt J, et al. Analysing chronic spinal changes in ankylosing spondylitis: a systematic comparison of conventional $x$ rays with magnetic resonance imaging using established and new scoring systems. Ann Rheum Dis 2004;63:1046-55. doi:10.1136/ard.2003.019968 [published Online First 5 April 2004]

14 Baraliakos X, Hermann KG, Landewe R, Listing J, Golder W, Brandt J, et al. Assessment of acute spinal inflammation in patients with ankylosing spondylitis by magnetic resonance imaging (MRI) - a comparison between contrast enhanced T1 and short-tau inversion recovery (STIR) sequences. Ann Rheum Dis. Published Online First 13 January 2005. doi:10.1136/ ard.2004.031609.

15 Melton LJ 3rd, Kan SH, Frye MA, Wahner HW, O'Fallon WM, Riggs BL. pidemiology of vertebral fractures in women. Am J Epidemiol 1989;129:1000-11.

16 Frei H, Oxland TR, Nolte LP. Thoracolumbar spine mechanics contrasted under compression and shear loading. J Orthop Res 2002;20:1333-8.

17 Harrison DE, Colloca CJ, Harrison DD, Janik TJ, Haas JW, Keller TS. Anterior thoracic posture increases thoracolumbar disc loading. Eur Spine J, 2004 May 27; [Epub ahead of print] 